\title{
Mechanical properties and vacuum tribological performance of Mo-S-N sputtered coatings
}

Kaushik Hebbar Kannur ${ }^{1,2 *}$, Talha Bin Yaqub $^{2,3}$, Christophe Pupier ${ }^{1}$, Christophe Héau ${ }^{1}$, Albano Cavaleiro $^{2}$

${ }^{1}$ IREIS, HEF Group, ZI Sud - Avenue Benoît Fourneyron, CS 42077 - 42162 AndrézieuxBouthéon, France

${ }^{2}$ University of Coimbra, Department of Mechanical Engineering, CEMMPRE, Rua Luís Reis Santos, 3030-788 Coimbra, Portugal.

${ }^{3}$ IPN - LED \& MAT - Instituto Pedro Nunes, Laboratory of Tests, Wear and Materials, Rua Pedro Nunes, 3030-199 Coimbra, Portugal.

*Corresponding author: Tel. +33 7678797 25, E-mail address: khebbarkannur.ireis@ @ef.fr 
XRD Analysis:-

Figure 1 shows the XRD patterns of pure $\mathrm{MoS}_{2}$ and Mo-S-N coatings. The pure $\mathrm{MoS}_{2}$ coatings were crystalline with a strong (100) peak. With the addition of $\mathrm{N}$, the (002) peak was suppressed and the (100) peak reduced the intensity due to the reduction of the size of $\mathrm{MoS}_{2}$ crystals and the formation of a nano-crystalline structure. A further increase in $\mathrm{N}$ led to the complete suppression of (100) peaks at 30 at. \% N. No significant structural changes were observed with the further increase of $\mathrm{N}$ content after 30 at. $\% \mathrm{~N}$.

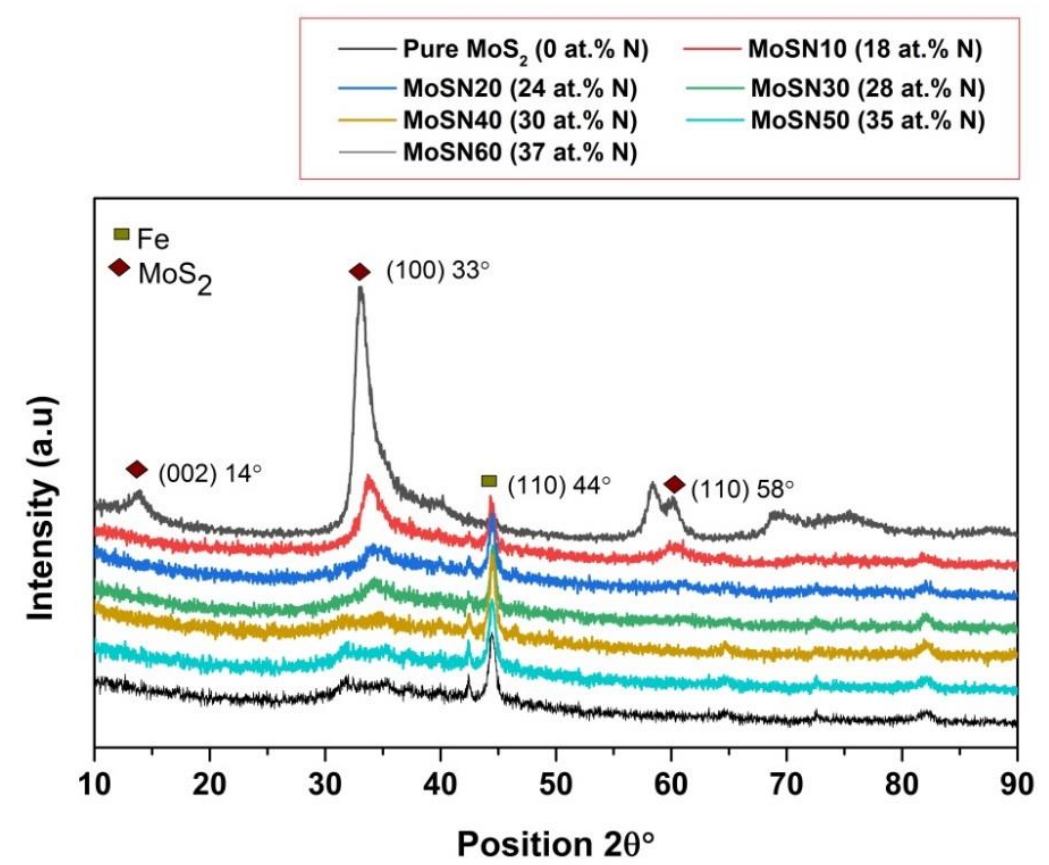

Figure 1:- Structural diffractograms of pure $\mathrm{MoS}_{2}$ and MoSN coatings from XRD analysis. 